\title{
A journey beyond the Gaussian world
}

\author{
An interview with Harry Joe
}

https://doi.org/10.1515/demo-2018-0016

Received October 12, 2018; accepted November 14, 2018

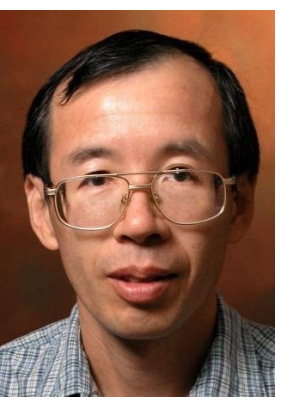

\begin{abstract}
Harry Joe is Professor of Statistics at the University of British Columbia, Vancouver, Canada. He received an Honors BSc in Mathematics from the University of Victoria in 1978, an MSc in Statistics from the University of British Columbia (UBC) in 1979, and a PhD in Statistics from Florida State University in 1982. He joined UBC as an Assistant Professor in 1982 and was promoted to the ranks of Associate and Full Professor in 1987 and 1993, respectively. He is renowned internationally for his pioneering work in dependence modeling, notably through three books. He has also made significant contributions in many other areas, including statistical computing, inference, and time series analysis. He has had successful collaborations in environmetrics, medical genetics and psychometrics. He was the 1995 winner of the Canadian Journal of Statistics Best Paper Award and the 2016 recipient of the Gold Medal for Research from the Statistical Society of Canada. He was John von Neumann Gastprofessur at Technische Universität München in MayJune 2011. He has also served the research community in various editorial capacities.
\end{abstract}

The eighth interview of the Dependence Modeling series features a conversation with Harry Joe. Harry's research is very broad. He has made key contributions to dependence modeling, time series analysis, composite likelihood techniques, and their applications in various contexts. He has also collaborated with researchers in many other fields, including psychometricians on limited information goodness-of-fit procedures for highdimensional ordinal response models, and geneticists with whom he developed and used statistical methods for the study of neurofibromatosis, a genetic disorder that causes tumors to form on nerve tissue. In the following, our questions to Harry are bold-faced.

\section{Background}

\section{Harry, could you please tell us a bit about your background and youth?}

I was born and raised in Victoria, which is the capital of British Columbia, on the West Coast of Canada. It is a relatively small but densely populated town with a high quality of life. Its Chinatown is the second oldest in North America after San Francisco. All this mattered to my parents, who immigrated from Guangzhou, China. We were two children at home. My brother and I both ended up having careers in science, I as a statistician and he as a computer scientist.

As far as I can remember, I was always good at mathematics. It was the easiest subject for me in high school, partly because it required the least memorization. I had already figured out by senior high school (grades 11 and 12 in Canada) that mathematics could be done from basic concepts and logical reasoning without needing to rely so much on memory. But in my high school days, I don't remember anyone telling me about career opportunities for those good at mathematics. I think my science teachers just suggested

\footnotetext{
Christian Genest: Department of Mathematics and Statistics, McGill University, Montréal (Québec) Canada.

^Corresponding Author: Giovanni Puccetti: Dipartimento di Economia, Management e Metodi Quantitativi, Università di Milano, Italy. E-mail: giovanni.puccetti@unimi.it
} 
to continue in the sciences at the university level. For me this meant mathematics, physics or chemistry as I didn't take biology in my final two years of high school. I did not have a childhood dream job and before my first university statistics course, I don't think I knew that there was such a thing as a professional statistician.

You did your undergraduate studies at the University of Victoria from 1974 to 1978. Who introduced you to statistics there, and how did you decide to specialize in this area?

My undergraduate degree was in Honors Mathematics with a Statistics emphasis. In second year, I took an introductory probability and statistics course from Roger Davidson, and I was exposed to some statistical methods in the lab component of an inorganic chemistry course. My other undergraduate instructors in statistics were Robert Odeh, Keith Hastings, and Bruce Johnson. I also took a course from Duane Meeter, who was visiting from Florida State University.

As an undergraduate, I viewed courses in statistics, operations research, numerical analysis and programming as being more applicable mathematics. Statistics emerged as a feasible option based on my undergraduate courses but I could have gone in other directions if my interest in the field had waned. One of my summer jobs was Fortran programming (with punched cards in those days). It was an excellent education and within my graduate cohort, I was ahead of others in preparation.

Then, you went on to do a Master's at the University of British Columbia (UBC) and a PhD at Florida State University. Who influenced you during your graduate studies?

I don't think anyone had a major influence on me but many had minor influences. John Petkau supervised my Master's thesis. Overall, I think that he and Jim Zidek had a substantial influence on me during my MSc program, and later as colleagues when I returned as a faculty member to UBC in 1982.

During my year in the MSc program, in 1978-79, I met Ingram Olkin, who was visiting from Stanford University and collaborating with Albert Marshall to complete their book on majorization and inequalities [20]. I was already exposed a little to majorization by Roger Davidson in a summer project.

Later at Florida State University, in Tallahassee, Mark Brown taught a course from the Marshall and Olkin book, and other researchers at that institution were using majorization and inequalities in their research. Frank Proschan was my PhD advisor. From him, via his well-known book with Barlow [2], I learned about reliability theory and concepts of bivariate and multivariate dependence; it is the latter that I then used in my research in dependence modeling. I completed my degree in 1982 (Figure 1).

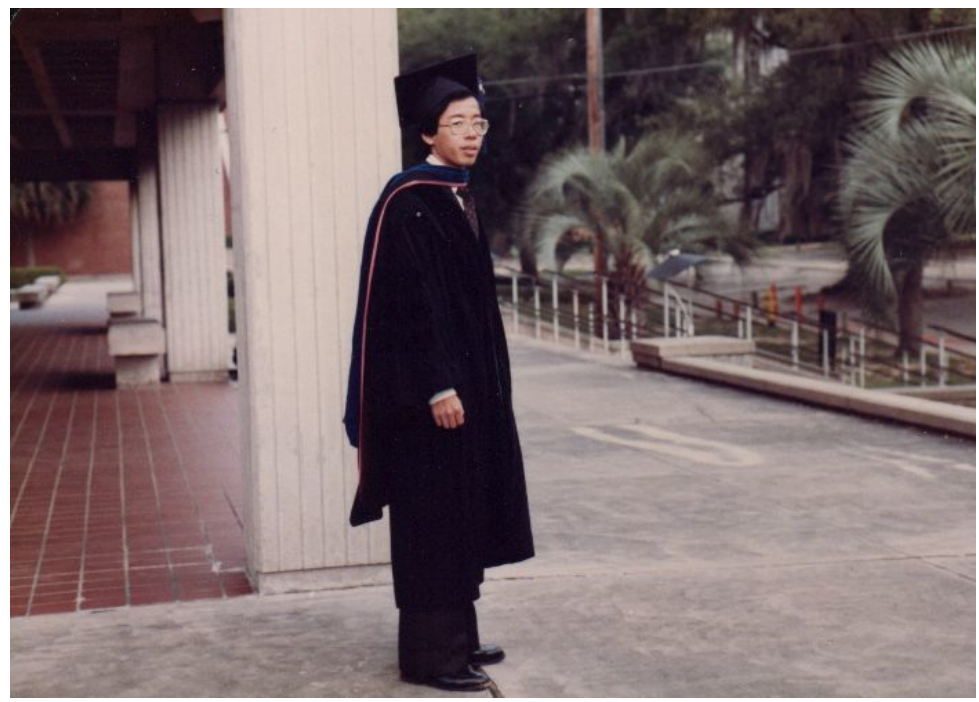

Figure 1: PhD regalia in 1982 after convocation in Tallahassee, Florida. 


\section{Academic career}

After completing your PhD in 1982, you were hired as an Assistant Professor at UBC. You have spent your entire career there. Were you ever tempted to move?

I was approached on occasion, but I did not consider alternatives to be appealing enough, even though the resources and environment at UBC are not completely satisfactory. After my $\mathrm{PhD}$ degree in the United States, for example, I did not consider that country as a place where I ever wanted to live. Canada is the main Western country that some of my relatives have immigrated to. I got used to the mild year-round climate in Vancouver, making it harder to consider living in places with more extreme temperatures. For dependence modeling applications in insurance and finance, however, Vancouver has disadvantages because the headquarters of Canadian banks and insurance companies are back East.

Nonetheless, you made extended research visits abroad over the years, including at Technische Universität München (TUM) as a John von Neumann Gastprofessur.

I visited various universities during my sabbatical leaves, most notably University College London, the University of Pittsburgh, and TUM. One of my most important sabbatical trips was from January to April 1994 in Pittsburgh, visiting Henry Block and Allan Sampson. I had the opportunity to teach a topics course in multivariate non-normal models, and while doing this, I had a very productive research period. Enough new ideas were developed in constructions of multivariate models and copulas that I was able to publish several papers from 1994 to 1997, followed by my first book [14]. Previous existing research on multivariate non-normal models was mainly devoted to the bivariate case and at that time, I considered it to be a difficult step to go from bivariate models to trivariate and higher-dimensional models.

Much later, in May-June 2011, through the efforts of Claudia Czado, I was invited by TUM as a John von Neumann Visiting Professor and taught a course entitled Copula Foundations and Applications (Figure 2). I used this opportunity to get started on my 2014 book [15]. It was also the chance to initiate collaborations with Claudia Czado, Anastasios Panagiotelis, Jakob Stöber, Eike Brechmann, and to contribute to the R package VineCopula.

In terms of teaching, what has been expected of you at UBC over the years?

At UBC, we are expected to teach a variety of undergraduate and graduate statistics courses to different audiences. Rarely do we teach a course on our current research. Only recently have we changed to a system

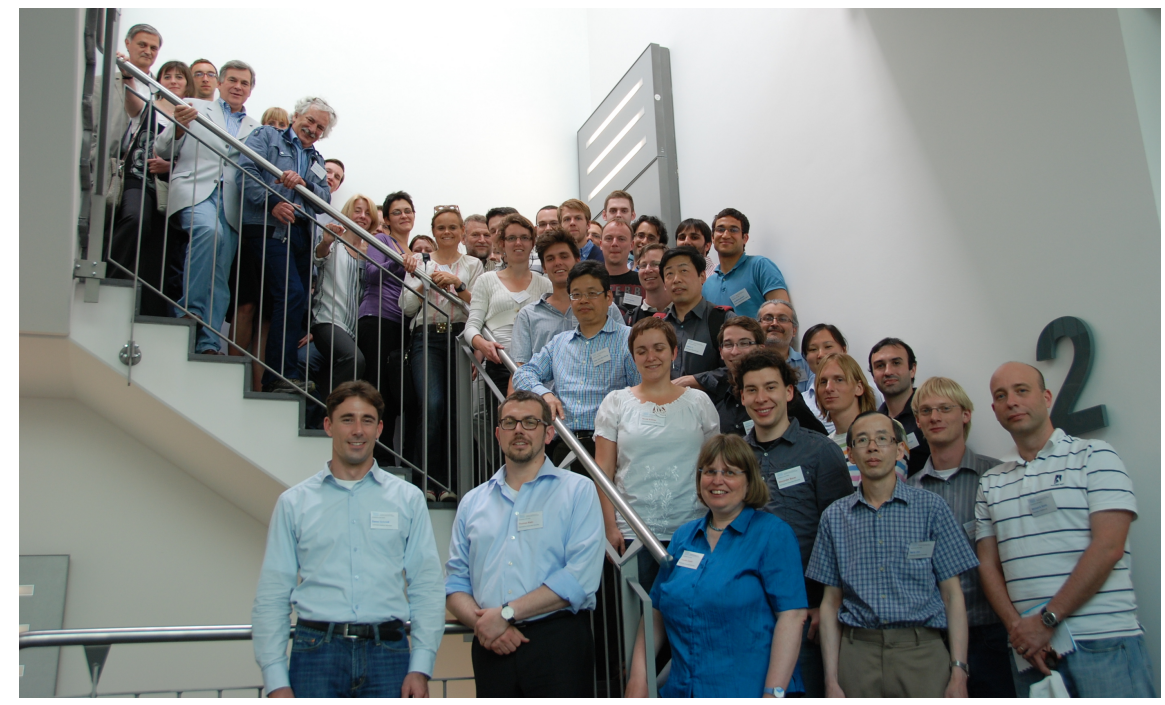

Figure 2: Group photograph at a conference on vines held in Munich in May 2011 while Harry (next to Claudia Czado in the front row) was a John von Neumann Gastprofessur. The conference was organized by Claudia and her colleagues. 
where we can teach an undergraduate course for several years in a row to develop and modernize the contents. With any course, though, it is possible to motivate and influence some of the top students.

At the undergraduate level, courses that I have taught most frequently in the past 10 years are Applied Regression Analysis and Design and Analysis of Experiments. In these and other undergraduate courses at the third- and fourth-year level, I require team project work. The idea is that students might be more motivated to study if they can see how the theory can be applied to something that they are specifically interested in. The range of ability and mastery of prerequisite courses is very wide by fourth year, which makes teaching a challenge. I usually have optional harder theoretical questions for bonus marks to challenge the top students and assess their capability for graduate studies.

At the graduate level, I have taught courses such as Time Series, Multivariate Statistical Analysis and Generalized Linear Models. I did teach a graduate course on copulas prior to the publishing of my recent book. Currently, I just make the web site available if a student wants a broad introduction to the construction and applications of copula models.

What do you see as the most important qualities of a university instructor?

A wide knowledge of their area of expertise, well beyond textbook knowledge. For statistics, it is important to show realistic examples as motivation of the theory. That's the ideal I try to pursue. Some students like my style of teaching but in course evaluations, I can sometimes receive criticism because a typical class has students with a wide range of abilities and interests, and it is not possible to please everyone. For example, some students find that my exams are too hard; this comment mainly comes from those who try to get by with memorization without understanding.

You have supervised many graduate students and postdoctoral fellows over the years. What is your approach to graduate supervision?

For research at the graduate level, I might provide a small research project that the student can get started with by reading relevant literature. My hope is then that the student can see how to develop an entire thesis. Alternatively and ideally, the student has an idea of a direction of research and it overlaps with my interests. A few of my past $\mathrm{PhD}$ students have (or will have) successful academic research careers; they include Taizhong $\mathrm{Hu}$, Lei Hua and Pavel Krupskii. These three were especially helpful as I was writing my two research monographs. Other former PhD students have done well in collaborative research and working in non-academia.

You have also had your share of administrative duties. In particular, you were Head of UBC's Statistics Department for a while. What was it like?

I was Head for three years from 1994 to 1997, and later Acting Head for four months in 2005. I did what I had to, but it was often frustrating. I found the UBC administration to be too bureaucratic in its procedures, and this continues to this day. Paul Gustafson was hired at the beginning of my Headship and has a very successful career. In 2005, with the Canada Research Chair (CRC) program and other openings, I was involved much more in interviewing and hiring negotiations. Jiahua Chen, previously at the University of Waterloo, is the only CRC still at UBC from such appointments in 2005.

\section{Research in dependence modeling and vine copulas}

\section{What were your initial interests in research?}

I was quite broad in consideration of research directions, and mainly I was interested in developing statistical theory and methods motivated by applications. After a few years, I found that it was challenging to study possible multivariate extensions of bivariate concepts.

In the summer of 1983, I was working with constrained majorization applied to an algorithm for computing the $p$-value for Fisher's exact test for two-way tables; the research appeared in Linear Algebra and its Applications [11]. This was my start into objects with given margins. This led to research on constrained majorization and dependence, and then multivariate distributions with given margins, multivariate non-Gaussian distributions, copulas, etc. For this reason, I read various papers by Maurice Fréchet and Giorgio Dall'Aglio, e.g., $[6,8]$, much earlier than papers on copulas per se. 


\section{What was your main motivation for research in dependence modeling?}

Because of other on-going research in the UBC Department of Statistics, part of my early motivation for investigating multivariate non-Gaussian distributions included multivariate/clustered/longitudinal models for discrete and binary responses. Also, for multivariate extremes, I was interested in finding a parametric family like the Gaussian with $d(d-1) / 2$ dependence parameters representing bivariate dependence for $d$ variables. These considerations led me into tail dependence for copulas. Applications in both of these areas also led to the "IFM method", a term coined by my PhD student James Jianmeng Xu in [26].

What did you see as some challenges for research in dependence modeling in the 1990s, and what are your views in hindsight?

For copulas, going from bivariate to trivariate and higher dimensions was difficult. In the early 1990s, the book references were Mardia [19] for bivariate models and Johnson and Kotz [18] for multivariate extensions; neither of these books explicitly defined the notion of copula, but they did have families of distributions with arbitrary univariate margins. A monograph by Hutchinson and Lai [10] appeared later which also had families of bivariate copulas.

I had recognized the D-vine (which I then called "sequential mixture of conditional distributions") as an approach to get flexible dependence in $d$ dimensions with the multivariate Gaussian law as a special case when the parametrization is converted to $d-1$ correlations and $(d-1)(d-2) / 2$ partial correlations. But in the 1990s, I was maybe too concerned with construction methods that are closed under margins, and I didn't have the computing capacity to go through the permutations of variables for the vine.

Nowadays for high dimensions, truncated vines make a lot of sense as a parsimonious dependence structure that can have a few layers on conditional dependence; the 1-truncated vine or Markov tree is generally too parsimonious.

With latent variables introduced into truncated vines to get factor copulas, there can be closure under margins. Similar to classical multivariate Gaussian factor structures based on a few latent variables, I would consider factor copulas as a good nonlinear dependence model to use, with or without conditional dependence given latent variables, when there are many variables with dependence that can be explained through some common sources.

Your 1997 research monograph Multivariate Models and Dependence Concepts [14] is a classic in dependence modeling. You also authored Dependence Modeling with Copulas [15], published in 2014. Tell us a bit about these two books.

In the 1990s, I thought one of the most glaring gaps in the literature was in models for multivariate statistical analysis without the classical Gaussian assumption. My 1997 research monograph has several (overlapping) techniques for constructing multivariate models, of which copulas are one tool. There are other constructions based on latent variables, random effects, mixtures, stochastic operators, thinning operators, and conditional specifications. These other construction methods are in more common use than copulas for multivariate and time series models with discrete response.

The 2014 monograph, as suggested by the title, is only on copulas. It expands dependence concepts from Chapters 2 and 3 of my 1997 monograph, and expands copula constructions and parametric copula families from Chapters 4 and 5 of the same book. There has been much research on copulas in between; space and time constraints did not allow me to cover all topics. I emphasized the topics that I use for applications that I was involved with, and this includes a diagnostic approach for deciding on copula models and assessing their fit.

Both books have data examples and case studies to showcase how copulas can be used for continuous and discrete responses. The 2014 book has a companion software (a self-contained R package that doesn't depend on upgrades to other packages) at the book's web site to show how the difficult numerical computations are done for data analyses, simulations, and copula properties. This was partly motivated by the software that is companion to the QRM book by McNeil, Frey and Embrechts [23]. This allows interested readers to check all computations, just like they can check the derivations and proofs.

Unlike the current trend, I made a conscious decision not to include any software code in my 2014 book. It has a chapter with many algorithms written in pseudo-code so that a reader could implement them without having to follow all of the details. Code can become dated and can be improved, but algorithms can withstand 
changes in the popularity of software. I have no intention of having a second edition of this book. If I write another book, it would be to cover some new developments since 2014.

Beyond your books, you published extensively in statistics and other fields. Looking at your CV, it seems that early on, you published mostly alone. Any reason why?

My early research consisted mostly of single-authored papers because the expectation for tenure and promotion at UBC was to develop independent directions of research. Also the Department of Statistics attracted few research students until the early 1990s. Once it did, I could engage more often in joint research leading to co-authored papers when supervising graduate students and having collaborative research grants, which for me were in environmetrics, mathematical psychology and medical genetics.

\section{How did you develop collaborations in other fields?}

From around 1985 to 1991, our department had a cooperative research grant in environmetrics; Jim Zidek and John Petkau were the principal investigators. This led Richard Smith and Ishay Weissman to visit over one summer when we were doing research on a bivariate threshold approach for extremes which led to paper [17]. Later, I, Christian, and others held a collaborative research grant in mathematical psychology with Tony Marley from McGill University as principal investigator. In that context, I attended a conference on random utility in psychology and economics, where I met Alberto Maydeu-Olivares with whom I ended up developing research for inference for models in psychometrics based on low-dimensional margins; see [16, 21, 22].

As for my collaboration in medical genetics, it was on Type 1 and Type 2 neurofibromatosis. This initiative started after a colleague from UBC's Department of Medical Genetics, Jan Friedman (MD, PhD) and one of his $\mathrm{PhD}$ students attended a seminar that I gave on the topic of multivariate discrete response models. Over the years, we wrote many papers together, starting with [25].

In 1995, you received an award for the best paper published in The Canadian Journal of Statistics in 1994. What was it about?

This is my paper entitled "Multivariate extreme-value distributions with applications to environmental data" [12]. It has results on extreme-value attractors from different constructions of multivariate copulas with upper tail dependence. Included is the limiting extreme-value copula from a D-vine copula in a couple of cases where the bivariate copulas at level 1 have upper tail dependence. These were applied up to dimension 5 and required numerical integration for the multivariate extreme value copula density. The application involved environmental data consisting of maximum ozone concentrations at several monitoring stations in the San Francisco Bay area and in the Greater Vancouver Regional District.

In 2016, you received the prestigious Gold Medal for Research from the Statistical Society of Canada. It celebrates your many achievements; which are you most proud of?

Overall, I would say that I am proud of being a major contributor to a "new" area of research, and writing a book on the topic before it became popular. I consider vines as one of my major contributions in dependence modeling. To me, copulas per se are a bit narrow as a research area, as the concept of a copula is just one of many useful ideas for the construction of multivariate non-Gaussian models.

My research has been mostly "multivariate" since around 1984. But there are only two periods where I have been very active in copula research: in the 1990s up to the publication of my 1997 monograph, and from 2007 onwards with the publication of my 2014 book. During the years 2006-2008 with workshops at Technische Universiteit Delft (Figure 3) and exposure to vines from Roger Cooke, Dorota Kurowicka, Kjersti Aas, Claudia Czado and their students, I saw the potential for more truly multivariate methodology for copula construction and applications. Haijun Li (while on sabbatical) and Aristidis Nikoloulopoulos (a postdoctoral fellow that Christian and I shared) visited me in the first half of 2008 and we had weekly meetings to discuss research in vines and copulas. Then I had two PhD students, Lei Hua and Pavel Krupskii, who made major conceptual contributions included in my 2014 book.

In the years 1997-2006, I had other PhD students and collaborators working on a variety of topics in dependence modeling. This included time series models for count data, inference for item response models in psychometrics based on low-dimensional margins, multivariate models with inference via composite likelihood, inference for familial data (as part of my medical genetics collaboration), and distributions for random correlation matrices based on partial correlations (the partial correlation vine is involved). 


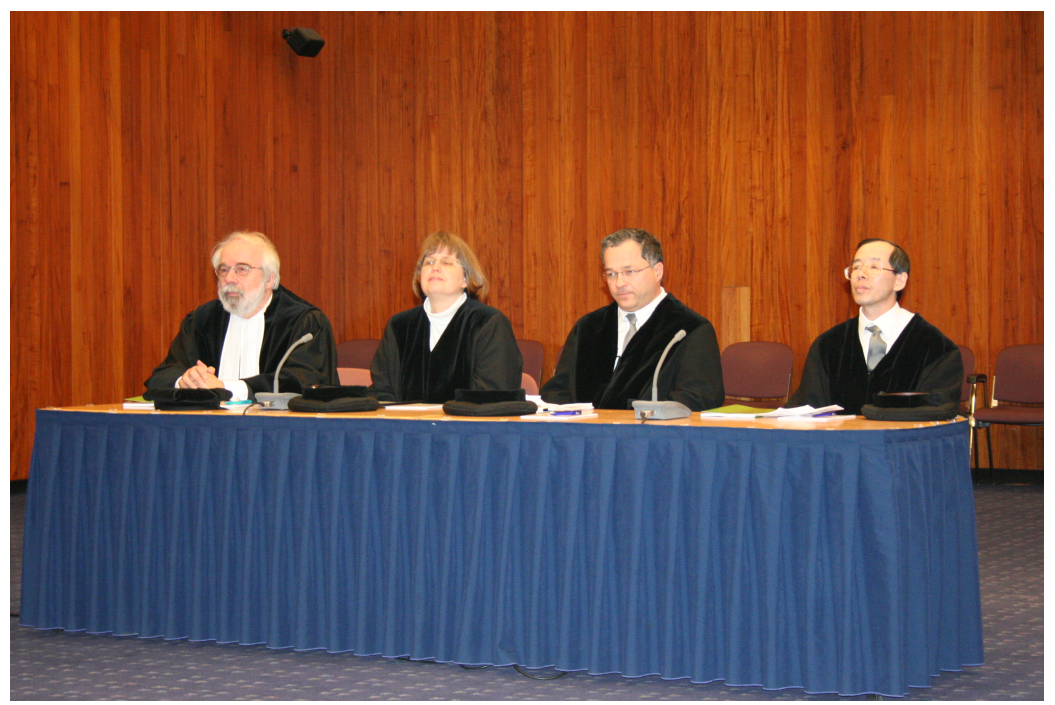

Figure 3: Photo of the PhD defense committee of Anca Hanea (a student of Roger Cooke and Dorota Kurowicka) at TU Delft on December 15, 2008. From left to right: Léon Rothkrantz, Claudia Czado, Christian Genest, and Harry Joe.

Roger Cooke has written his side of the story about the origin of vines in an interview for this journal [7]. What is yours?

Roger Cooke and Tim Bedford [3, 4] developed the main ideas of the vine as a graphical object. I developed in [13] the idea of what is now called the "vine copula" or "pair-copula construction" with a sequential mixture of conditional distributions based on bivariate copulas. I only had the case of the linear vine (now called Dvine) for which no proofs are needed in terms of graphical objects. On this particular vine, I had assigned bivariate copulas representing bivariate dependence to the first level and then bivariate copulas representing bivariate conditional dependence to the subsequent levels. With the many different ways of constructing the vine layers of trees, it is obvious that one can assign bivariate copulas to the edges of the trees at different levels with interpretation of conditional dependence for trees beyond level 1 . This makes use of the Fréchet class of two (k-1)-dimensional marginal distributions with $k-2$ variables in common, such as $F_{S \cup\{a\}}, F_{S \cup\{b\}}$, where $S$ is an index set of size $k-2$ with $k \geq 3$ and $a, b \notin S$; see Section 4.5 of [14].

Roger Cooke said that it took five years for his paper [4] with Tom Bedford to appear in The Annals of Statistics. Is it worth waiting that long to publish in a top-tier journal?

Personally, I find that with students as collaborators, it is better to aim for journals with a quicker turnaround time. And there are many top-tier venues with faster response times. When thinking where to submit a new paper, I mainly consider journals with articles on topics related to mine. Nowadays, statistics journals tend to favor different types of research, even if the journal name is not linked to a subarea of statistics. In the past two decades, the Journal of Multivariate Analysis has emerged as the leading journal for theoretical contributions to dependence modeling, and it has featured three Special Issues on dependence modeling with copulas; I served as Guest Editor for one of them (vol. 138, 2015).

As a pioneer in dependence modeling, what do you regard as the important aspects that deserve research, and what do you think could be the next big thing after vine copulas?

High-dimensional problems are one major challenge. One possible approach for the very highdimensional case, which I mention in Section 3.11 of my 2014 book [15], is to develop models for smaller groups of homogeneous variables and then have a second step of modeling the between-group dependence. A good starting point is Dominik Müller's PhD thesis [24], supervised by Claudia Czado.

Also variations of factor copulas can be useful for high-dimensional applications if (some of) the dependence can be explained with latent variables. My approach for factor copulas has been to introduce latent variables into the vine, and I think much more can be done in this direction. 


\section{Do you have any concerns on current directions in copula applications?}

One concern is that some papers just use a few one-parameter copula families with or without vines. But my experience is that these simple one-parametric families do not fit data well when the sample size exceeds 500 to 1000 and dependence is moderate to strong. Data analysts do need to be aware of 2- and 3-parameter families that can be used when dependence is stronger and there can be various forms of tail asymmetry that can be seen, e.g., on plots after univariate transforms to $\mathcal{N}(0,1)$. An analogy is that we know that we need to go beyond 1- and 2-parameter families for fitting univariate models when the sample size exceeds a few hundreds in order to accommodate skewness and tail properties.

\section{A motley crew of reflections}

You are now in your sixties but still going strong, and there is no mandatory retirement age in Canada. You still have lots of research projects in mind, don't you?

Yes, I think I can do much more. I have files of research problems that I haven't had time to develop further, and some are too theoretical for the types of students in our graduate program. Also, I would like to see if copulas can have more significant applications in different areas.

Is there something in your career that you regret or wish you could now change?

No. Some things I could not do, of course, such as more travel and conferences because I have difficulty adjusting to time zone differences.

These days, it seems that more and more students are attracted by machine learning and "data science" as opposed to statistics. How do you feel about this?

When my students have an interest in machine learning or data science, I feel compelled to encourage them because this will be where there are jobs in the future for people with a statistics and computing background. This being said, traditional statistical approaches to data analysis and inference are still relevant as they might lead to more interpretable models.

What would be your advice to young researchers who would like to emulate you in multitasking and keeping a high level of productivity?

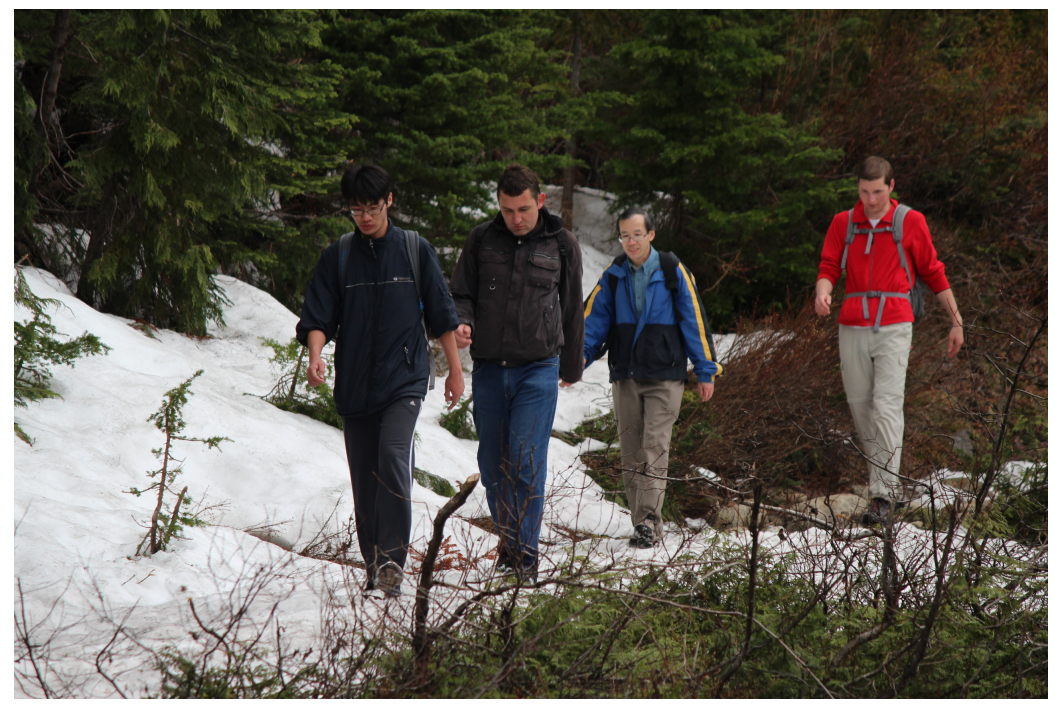

Figure 4: Mountain hike at Mount Seymour, North Vancouver, in June 2012. From left to right: Chao Xiong, Pavel Krupskii, Harry Joe, and Eike Brechmann; photo taken by UBC Statistics Professor Matías Salibián-Barrera. 


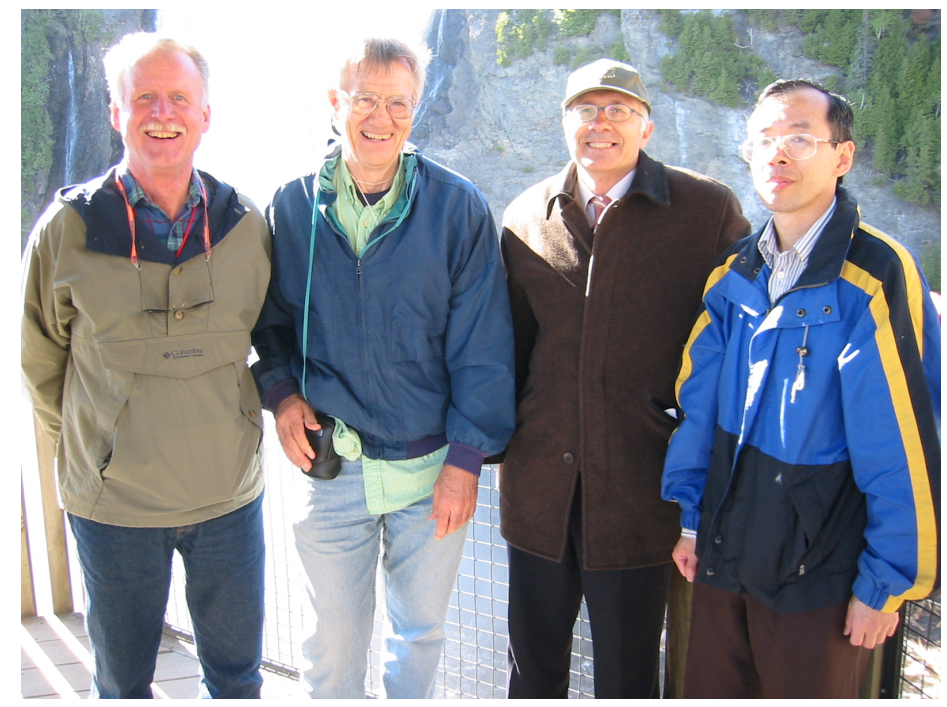

Figure 5: Photo taken at Montmorency Falls, near Québec, during the conference Dependence Modeling: Statistical Theory and Applications in Finance and Insurance organized by Christian Genest and Michel Gendron in May 2004; see [9]. From left to right: Roger Nelsen, Barry Arnold, Carles Cuadras, and Harry Joe. Barry Arnold, former Editor-in-Chief of the Journal of Multivariate Analysis, has published a Springer book [1] in 1999 with Castillo and Sarabia entitled Conditional Specifications of Statistical Models. Carles Cuadras and his colleagues organized the conference Distributions with Given Marginals and Statistical Modelling in Barcelona in 2000; see [5].

I would say don't be too narrow in what you study in graduate school. For someone planning a research career, anything that is learned might be useful later as research broadens into different theoretical topics and application areas. Be curious, ask questions, and stay fit!

\section{Do you have a favorite hobby or activity?}

I am quite fond of racket sports; I have played tennis and table tennis regularly since my graduate student days, and then later took up squash. I consider these as non-serious activities as I don't want to think too much in my leisure time activities. As a graduate student, I practiced these sports with several of my professors such as Ralph Bradley and Pi-Erh Lin. As a professor, I have continued to be involved in these sports with colleagues and many students over the years. It has been a good way to build friendships and have fun. On occasion I also enjoy walks and hikes with students and colleagues (Figures 4-5).

Acknowledgments and credits. Thank you for granting us this interview, Harry, and for being such an inspiring leader. We wish you continuing success in your research and a long, healthy life ahead. Unless explicitly mentioned, all photographs are courtesy of Harry Joe or Christian Genest.

\section{References}

[1] Arnold, B.C., E. Castillo, and J.M. Sarabia (1999). Conditional Specification of Statistical Models. Springer-Verlag, New York.

[2] Barlow, R.E. and F. Proschan (1981). Statistical Theory of Reliability and Life Testing. To Begin With, Silver Spring MD.

[3] Bedford, T. and R.M. Cooke (2001). Probability density decomposition for conditionally dependent random variables modeled by vines. Ann. Math. Artif. Intell. 32, 245-268.

[4] Bedford, T. and R.M. Cooke (2002). Vines: A new graphical model for dependent random variables. Ann. Statist. 30(4), 10311068.

[5] Cuadras, C.M., J. Fortiana, and J.A. Rodríguez-Lallena, editors. (2002). Distributions with Given Marginals and Statistical Modelling. Kluwer Academic Publishers, Dordrecht.

[6] Dall'Aglio, G. (1972). Fréchet classes and compatibility of distribution functions. In Symposia Mathematica, Vol. IX, pp. 131150. Academic Press, London. 
[7] Durante, F., G. Puccetti, M. Scherer, and S. Vanduffel (2017). The vine philosopher: An interview with Roger Cooke. Depend. Model. 5, 256-267.

[8] Fréchet, M. (1951). Sur les tableaux de corrélation dont les marges sont données. Ann. Univ. Lyon I, Sect. A. 14, 53-77.

[9] Genest, C. (2004). DeMoSTAFI conference. Liaison 18 (3), 13-14.

[10] Hutchinson, T.P. and C.D. Lai (1990). Continuous Bivariate Distributions, Emphasising Applications. Rumsby, Sydney.

[11] Joe, H. (1985). An ordering of dependence for contingency tables. Linear Algebra Appl. 70, 89-103.

[12] Joe, H. (1994). Multivariate extreme-value distributions with applications to environmental data. Canad. J. Statist. 22(1), 47-64.

[13] Joe, H. (1996). Families of $m$-variate distributions with given margins and $m(m-1) / 2$ bivariate dependence parameters. In Rüschendorf, L., B. Schweizer and M.D. Taylor (Eds.), Distributions with Fixed Marginals and Related Topics, pp. 120-141, Institute of Mathematical Statistics, Hayward CA.

[14] Joe, H. (1997). Multivariate Models and Dependence Concepts. Chapman \& Hall, London.

[15] Joe, H. (2014). Dependence Modeling with Copulas. Chapman \& Hall/CRC, Boca Raton FL.

[16] Joe, H. and A. Maydeu-Olivares (2010). A general family of limited information goodness-of-fit statistics for multinomial data. Psychometrika 75(3), 393-419.

[17] Joe, H., R.L. Smith, and I. Weissman (1992). Bivariate threshold methods for extremes. J. R. Stat. Soc. Ser. B 54(1), $171-183$.

[18] Johnson, N.L. and S. Kotz (1972). Continuous Multivariate Distributions. Wiley, New York.

[19] Mardia, K.V. (1970). Families of Bivariate Distributions. Griffin, London.

[20] Marshall, A.W. and I. Olkin (1979). Inequalities: Theory of Majorization and Its Applications. Academic Press, New York.

[21] Maydeu-Olivares, A. and H. Joe (2005). Limited- and full-information estimation and goodness-of-fit testing in $2^{n}$ contingency tables: A unified framework. J. Amer. Statist. Assoc. 100(471), 1009-1020.

[22] Maydeu-Olivares, A. and H. Joe (2006). Limited information goodness-of-fit testing in multidimensional contingency tables. Psychometrika 71, 713-732.

[23] McNeil, A.J., R. Frey, and P. Embrechts (2015). Quantitative Risk Management: Concepts, Techniques and Tools. Revised Edition. Princeton University Press.

[24] Müller, D.T. (2017). Selection of Sparse Vine Copulas in Ultra High Dimensions. PhD thesis, Technische Universität München. Available at https://mediatum.ub.tum.de/1382835.

[25] Szudek, J., H. Joe, and J.M. Friedman (2002). Analysis of intra-familial phenotypic variation in neurofibromatosis 1 (Nf1). Genetic Epidemiol. 23(2), 150-164.

[26] Xu, J.J. (1996). Statistical Modelling and Inference for Multivariate and Longitudinal Discrete Response Data. PhD thesis, University of British Columbia. Available at https://open.library.ubc.ca/clRcle/collections/ubctheses/831/items/1.0087914. 